\title{
Do women seeking termination of pregnancy need pre-abortion counselling?
}

\author{
Charlotte Baron, ${ }^{1}$ Sharon Cameron, ${ }^{2}$ Anne Johnstone ${ }^{3}$
}

- Additional material is published online only. To view please visit the journal online (http://dx.doi.org/10.1136/jfprhc 2014-101161)

${ }^{1}$ Medical Student, University of Edinburgh Medical School, Edinburgh, UK

${ }^{2}$ Consultant Gynaecologist, Chalmers Sexual and Reproductive Health Service, Edinburgh, UK

${ }^{3}$ Research Nurse, Chalmers Sexual and Reproductive Health Service, Edinburgh, UK

\section{Correspondence to}

Ms Charlotte Baron, University of Edinburgh Medical School, 47 Little France Crescent, Edinburgh EH16 4TJ, UK; s1101681@sms.ed.ac.uk

Received 11 December 2014 Revised 21 February 2015 Accepted 11 May 2015

\section{CrossMark}

To cite: Baron C, Cameron S,
Johnstone A. J Fam Plann
Reprod Health Care
2015;41:181-185.

\section{ABSTRACT}

Background Pre-termination counselling is currently voluntary in the UK; however, there has been political debate regarding the introduction of mandatory pre-termination counselling as well as who should be providing the abortion counselling services.

Objective To quantify the proportion of women who use pre-termination counselling services and to evaluate their experience.

Method An anonymous self-administered questionnaire of women requesting an abortion at Chalmers Sexual Health Centre and the Royal Infirmary of Edinburgh NHS Lothian from 6 October to 2 December 2014.

Results Only 18 (9\%) of the 201 women surveyed reported using pre-termination counselling. The majority of women did not feel counselling was necessary because they were already certain of their decision. Nearly a quarter (22\%) of women claimed to not know counselling was available. Women who did use counselling were satisfied with the services they received. The majority of counselling services were provided by the National Health Service and only one woman used a 'pro-life' charity. Women stated that they would prefer face-toface counselling rather than telephone or Internet-based counselling.

Conclusions Most women do not seem to want or need pre-termination counselling therefore policies aimed at mandatory counselling, would be contrary to women's wishes. Counselling should be targeted at women with risk factors for psychological complications post-termination.

\section{INTRODUCTION}

Abortion was legalised in Great Britain under the 1967 Abortion Act. ${ }^{1}$ More than 200000 abortions are now carried out in Britain each year, 12000 of which are performed in Scotland. ${ }^{2}$ Nearly all abortions carried out in England and

\section{Key message points}

- Pre-termination counselling is not wanted or needed by the majority of women because they are already certain of their decision.

- Policies aimed at mandatory pretermination counselling would be a waste of resources and contrary to women's wishes.

- Health care professionals should identify women at risk of psychological complications post-termination so that counselling can be targeted at those most at risk.

Wales are funded by the National Health Service (NHS) but over half take place in private clinics under NHS contract. ${ }^{2}$ In contrast, $99.7 \%$ of all abortions in Scotland are both funded by and carried out in NHS premises. ${ }^{4}$ It is estimated that at least one in three women will undergo a termination of pregnancy (TOP) by the age of 45 years. ${ }^{1}$ Therefore although it is a subject that provokes ethical and legal debate, it remains an important aspect of health care for women.

It is common for women to experience a range of emotions after abortion including regret, guilt, sadness and relief. However, very few women suffer any long-term psychological morbidity, with the incidence of depression post-abortion equalling the rate amongst all women aged 15-35 years. ${ }^{5-8}$ Risk factors for psychological complications following abortion include a history of mental health problems, a poor network of support, late gestation and younger age (particularly those aged under 16 years). ${ }^{9}$ Current guidelines published by the 
Royal College of Obstetricians and Gynaecologists (RCOG) state that women requesting an abortion should have access to counselling and decision-making support if they require them. ${ }^{1}$ However, they advise that women who are certain of their decision should not be subjected to mandatory counselling. ${ }^{1}$

The term 'counselling' should be interpreted with caution as it can refer to a spectrum of meanings from simple information exchange to intensive psychiatric counselling. The RCOG identifies three types of counselling that women may require within an abortion setting. ${ }^{1}$ First, implications counselling offers pregnant women the opportunity to talk through and better understand the implications of their proposed course of action, both for themselves and for their family. Second, support counselling provides emotional support to women and their partners during a particularly stressful time in their lives. The third type is therapeutic counselling, which takes place after a termination and helps women to deal with any problems that have arisen from the abortion, both practically and emotionally.

The attitude towards abortion counselling varies greatly between countries. Pre-abortion counselling is mandatory in 32 of the 50 American states as well as in some European countries including Belgium and Germany. ${ }^{10}$ Benefits of counselling, including the potential to reduce the severity of any psychological sequelae, have not been substantiated by evidence. ${ }^{9} 11$ However, a study carried out in Belgium, where preabortion counselling is mandatory, found that women were very satisfied with the counselling they received. Before the counselling, women were hesitant about its benefits because most felt sure of their decision. However, after the counselling, women were found to be less distressed and show greater decisiveness, showing that counselling may have a role in increasing a woman's confidence in her decision. ${ }^{12}$

Abortion counselling has attracted recent political interest in the UK, first as to whether pre-abortion counselling should be compulsory and second about who should provide the abortion counselling services. In 2011, an amendment to the law was proposed for pre-abortion counselling to be made compulsory for women requesting an abortion. ${ }^{13}$ This did not receive significant parliamentary support so instead a second amendment was proposed to give women the option of counselling, but this was to be delivered only by 'independent' organisations. ${ }^{13}$ 'Independent' was defined as the NHS or a private body that does not itself provide abortion procedures. ${ }^{14}$ This would have prevented those non-profit charity-run clinics that are NHS-funded from offering counselling due to concerns over a supposed financial conflict of interest. ${ }^{13}$ In practice this would therefore have meant that women having terminations in NHS-funded agencies would not have access to counselling services from their abortion provider. The amendment was debated in parliament in September 2011 and was not passed. The Government did, however, agree to a cross-party enquiry to look into counselling services and unintended pregnancies. ${ }^{13}$ Advice to commissioners of services subsequently issued in England states that all service providers should ensure that there is access to appropriately trained counsellors for all women who accept the offer of counselling. ${ }^{15}$

Currently a range of counselling services exists for women in the UK requesting an abortion who choose to use them. These comprise NHS counselling services, mainly based in general practitioner (GP) practices and sexual and reproductive health (SRH) centres, and independent organisations including Marie Stopes International, British Pregnancy Advisory Service (BPAS) and some so-called 'pro-life' (i.e. opposed to abortion) charities. Although it is understood that only a minority of women in the UK who are considering an abortion actually use counselling services, there has been little research to quantify the exact proportion of women who do so. ${ }^{9} 16$

The aim of this study was therefore to establish the proportion of women presenting for TOP to NHS abortion services in Edinburgh, Scotland who use any of the three types of counselling identified by the $\mathrm{RCOG}^{1}$ and to evaluate their experience of them.

\section{METHODS}

An anonymous self-administered questionnaire to evaluate the use and quality of counselling services was developed and refined with the input of key stakeholders including doctors and nurses working in the abortion service. The survey was piloted among eight women and from this minor adjustments were made to produce the final questionnaire.

Questionnaires were distributed to women requesting an abortion at either the Chalmers Sexual Health Centre (Chalmers) or the Royal Infirmary of Edinburgh (RIE) over a 9-week period between 6 October and 2 December 2014. These services account for $80 \%$ of the abortion workload within the region (approximately 2000 abortions per year). ${ }^{3}$ Women are given an appointment to be seen at one of these clinics by the centralised referral service that accepts referrals from GPs, SRH services (including nurse-led clinics) as well as direct hospital referrals. The questionnaires were handed out to women by clinic reception staff when they arrived for their appointment, and women were instructed to place their completed questionnaires in a clearly marked sealed box in the waiting area before they saw any health care professional. Women were reassured that the questionnaire was anonymous and would not affect their treatment in any way. The exclusion criterion for distribution was any patient judged by the reception staff to be too distressed.

The questionnaire comprised a short introduction followed by questions regarding women's use and 
views of counselling services (see online-only Supplementary Material: Appendix 1). Women were asked to complete different sections of the survey according to whether or not they had used counselling services. Questions included simple tick boxes, responses to statements using a Likert scale and additional space for free text. Simple patient demographic information was also collected including age, postcode (used to derive a deprivation category score) ${ }^{10}$ and reproductive history. Question sequence was carefully chosen to ensure that the initial questions would motivate a reply and sensitive demographic questions were placed at the end. The questionnaire was approved by the local Sexual Health Quality Improvement Team but was judged not to require formal ethical approval by the medical ethics committee at the University of Edinburgh.

\section{Statistics}

The questionnaires were coded and the data were entered into a Microsoft Excel ${ }^{\mathrm{TM}}$ spreadsheet. Data analysis was carried out using Microsoft Excel formulae. GraphPad Software was used to perform a Fisher Exact test and a $p$ value $<0.05$ was considered to be statistically significant.

\section{RESULTS}

In total, 358 women attended requesting TOP at the two centres over the study period. Questionnaires were distributed to 264 (74\%) women and 201 (76\%) were returned. The respondents' demographics are shown in Table 1 . The mean age of the respondents was 26 (range 14-45) years.

Only 18 (9\%) women reported using counselling services before attending their appointment. Of those who did not use counselling, 156 (85\%) women said it was because they were already sure of their decision

Table 1 Demographics of the study population $(n=201)$

\begin{tabular}{lr}
\hline Demographic & $\boldsymbol{n}(\%)$ \\
\hline Age (years) & \\
$\leq 16$ & $8(4)$ \\
$17-21$ & $48(24)$ \\
$22-28$ & $74(37)$ \\
$29-35$ & $35(17)$ \\
$36-44$ & $24(12)$ \\
Not answered & $12(6)$ \\
Reproductive history & \\
Previous termination & $66(33)$ \\
Previous birth & $82(41)$ \\
Deprivation score* & \\
1-2 (Affluent) & $21(10)$ \\
$3-5$ (Moderately deprived) & $136(68)$ \\
$6-7$ (Severely deprived) & $25(12)$ \\
Not answered & $19(10)$ \\
\hline
\end{tabular}

*Based upon Scottish postcodes. ${ }^{10}$ or because they expected to receive sufficient information at their appointment, suggesting that most women do not need pre-termination counselling. Forty $(22 \%)$ women did not know that counselling services were available. Although the questionnaire mainly concerned pre-termination counselling, there was a single question about predicted use of posttermination counselling. A significantly higher proportion of women who had used a pre-termination counselling service indicated that they thought they would use post-abortion counselling compared to those who had not used any counselling services ( $50 \%$ vs $21 \%, p=0.04)$.

Demographic characteristics were identified for the women who used pre-abortion counselling services (Table 2). There was no significant difference in demographic characteristics of women who had used preabortion counselling compared to those who had not. Women who had used pre-abortion counselling were generally satisfied with the services they received; all but one of the women rated their counselling as 'Excellent' or 'OK' and none of the women stated that they felt pressurised by their counsellor to make a particular decision about continuing their pregnancy or not. However, only $10(56 \%)$ women said that they thought counselling had helped them to make a decision.

In terms of counselling services, the majority of those who had used counselling $(n=13,72 \%)$ chose NHS-run services based in GP practices and SRH centres. Of the small number $(n=5)$ who used private counselling services, only one woman used a 'pro-life' charity (Lifeline). In terms of the method of counselling delivery, 15 (83\%) women used face-to-face counselling. The only respondents to use another method of delivery were three women who chose a private provider telephone counselling service. The popularity of face-to-face counselling was further highlighted by $78 \%$ of all respondents choosing it as their preferred type of counselling, with only a minority favouring telephone $(n=2,11 \%)$ or online $(n=2$, $11 \%)$ services.

Table 2 Demographics according to whether counselling was used

\begin{tabular}{lcc}
\hline Demographic & $\begin{array}{l}\text { Counselling } \\
{[\boldsymbol{n}(\%)]}\end{array}$ & $\begin{array}{l}\text { No counselling } \\
{[\boldsymbol{n}(\%)]}\end{array}$ \\
\hline Age $<25$ years & $4(24)$ & $83(48)$ \\
Age $\geq 25$ years & $13(76)$ & $89(52)$ \\
Previous termination & $7(39)$ & $59(35)$ \\
No previous termination & $11(61)$ & $109(65)$ \\
Previous birth & $11(61)$ & $71(38)$ \\
Deprivation score* & & \\
1-2 (Affluent) & $3(18)$ & $18(10)$ \\
3-5 (Moderately deprived) & $10(59)$ & $126(73)$ \\
6-7 (Severely deprived) & $4(24)$ & $21(12)$ \\
\hline
\end{tabular}

${ }^{*}$ Based upon Scottish postcodes. ${ }^{10}$ 


\section{DISCUSSION}

The present study showed that the majority of women chose not to use counselling services and that this was because they were already sure of their decision. This is not surprising since research has previously shown that most women make a decision on the outcome of an unintended pregnancy at the time of taking a pregnancy test. ${ }^{9}{ }^{16}$ Separate Swedish and American studies found that three-quarters of women have decided on a provisional course of action even before taking a pregnancy test. ${ }^{17} \quad 18$ Similarly, a qualitative study found that over half of women had completed the decision-making process before making any contact with health care professionals. ${ }^{19}$ Although the latter was an older study (published in 1985), it shows that women's ability to make a quick decision on their course of action is not something that has changed over time. This therefore raises the question as to just how valuable pre-abortion counselling is for women who are certain of their decision; surely mandatory counselling is an additional burden for women who have already made up their mind? Furthermore, obligatory counselling delays the abortion process, prolonging the stress and anxiety for women, which has been found to increase the risk of both morbidity and mortality post-abortion. ${ }^{9}$ In the present study, just over half the women who sought counselling felt that it helped them to make a decision, although almost all expressed satisfaction with the service. This suggests that counselling may play a more important role in terms of providing support and reassurance for women rather than objectively aiding the decisionmaking process. Indeed previous research from the same service that used a validated measure of intendedness of pregnancy (London Measure of Unintended Pregnancy) demonstrated that most women requesting an abortion had a clearly unintended pregnancy, were certain of their decision and did not desire further counselling. ${ }^{20}$

Nearly one-quarter of women stated that they did not realise pre-abortion counselling services were available. However, given the study design we do not know how many of these women would have taken up the services if offered. Nevertheless, this study highlights the importance of GPs and other health professionals who refer women for abortion making women aware of the services that are available when referring them for abortion, as well as ensuring that abortion providers themselves more clearly advertise availability of counselling services.

Given that most women do not appear to need or want pre-abortion counselling, it would be sensible to focus resources on those women most at risk of psychological morbidity post-termination. ${ }^{9}{ }^{21}$ However, it is important to highlight that there is no evidence to show that pre-abortion counselling reduces the incidence of psychological sequelae post-abortion. ${ }^{11}$ Some experts suggest that women requesting an abortion should be screened for factors known to be associated with psychological complications such as history of mental health problems, poor social support and advanced gestation. ${ }^{92}$ We did not find any differences in the demographics of women who used counselling compared to those who did not. This may be due to the small number of women who used counselling in the study population. Although nonsignificant, women using pre-abortion counselling services tended to be older (aged $>25$ years), have children and live in more deprived areas than those who did not.

A simple Internet search for abortion counselling in the UK generates hundreds of results, showing just how many different types of counselling services are available to women. Of the women we surveyed, face-to-face counselling was the most common, with only three women using telephone counselling and none using online counselling. Telephone counselling has proved popular in remote areas such as parts of British Columbia, Canada ${ }^{23}$ and may be more valuable in remote areas of the UK where face-to-face counselling is less readily available. With the rise in the use of the Internet it is somewhat surprising that online counselling was not as popular among the women we surveyed. An Australian study investigating the motives of adolescents who used Internet counselling found that it is the privacy and anonymity aspects that are most appealing. ${ }^{24}$ Those interviewed liked the non-confrontational environment and were reassured knowing that there was no risk of being overheard. Some even felt it was easier to coherently convey their emotions in written text as opposed to oral communication. ${ }^{21}{ }^{24}$ Although the latter research was not specific to counselling in an abortion setting, it does nevertheless highlight some of the priorities young people have when choosing a counselling method.

A strength of our study is that women possessed similar demographics to the larger population of women requesting abortion in the region. However, it is possible that our study may not represent opinions of women from remote and rural parts of the country or those seeking abortion in the private sector. Another weakness is that women who chose to complete the questionnaire may differ from those who declined. We cannot exclude the possibility that women who are certain of their decision may have been more willing to complete the questionnaire than those who were particularly worried or distressed. This is significant because pre-abortion counselling is more relevant for these anxious and upset women. Furthermore, although we had high response rates, we know that one-quarter of women attending the clinic were not given a questionnaire. The study relied on the goodwill of reception staff and therefore due to job pressures the reception staff may have omitted to give all women a questionnaire to complete. The survey did not include any questions about the mental 
health history of respondents, and with the benefit of hindsight this would have been valuable in identifying any women who could be specifically targeted to receive counselling.

\section{CONCLUSIONS}

Few women currently use pre-abortion counselling services in the setting under investigation, stating that they are already certain of their decision regarding TOP and do not need additional support. Consequently policies aimed at mandatory counselling would be a waste of resources and contrary to women's wishes. Health care professionals working in an abortion setting should, however, be aware of risk factors for poor psychological outcome post-abortion so that they can specifically target counselling services to these women.

Acknowledgements The authors are grateful to the clinical and research staff at the Royal Infirmary of Edinburgh and Chalmers Sexual and Reproductive Health Centre for their help and support throughout this project. They would also like to thank all the women who took the time to complete a questionnaire.

Competing interests None declared.

Provenance and peer review Not commissioned; externally peer reviewed.

\section{REFERENCES}

1 Royal College of Obstetricians and Gynaecologists. The Care of Women Requesting Induced Abortion. London, UK: Royal College of Obstetricians and Gynaecologists, 2011.

2 Department of Health. Abortion Statistics, England and Wales, 2013. London, UK: Department of Health, 2014.

3 Information Services Division (ISD) Scotland. Abortion Statistics. Year ending 31st December 2012. 2013. https:// isdscotland.scot.nhs.uk/Health-Topics/Sexual-Health/ Publications/2013-05-28/2013-05-28-Abortions-Report.pdf? 82600039244 [accessed 24 November 2014].

4 Information Services Division (ISD) Scotland. Abortion Statistics. Year ending 31st December 2009. 2010. http://www. isdscotland.scot.nhs.uk/Health-Topics/Maternity-and-Births/ Publications/2010-05-25/2010-05-25-Abortions-Report.pdf? [accessed 24 November 2014].

5 Cameron S. Induced abortion and psychological sequelae. Best Pract Clin Obstet Gynaecol 2010;24:657-665.

6 Charles VE, Polis CB, Sridhara SK, et al. Abortion and long-term mental health outcomes: a systematic review of the evidence. Contraception 2008;78:436-450.

7 Handy J. Psychological and social aspects of induced abortion. Br J Clin Psychol 1982;21:29-41.
8 Astbury-Ward E. Emotional and psychological impact of abortion: a critique of the literature. J Fam Plann Reprod Health Care 2008;34:181-184.

9 Rowlands S. The decision to opt for abortion. J Fam Plann Reprod Heath Care 2008;34:175-180.

10 Guttmacher Institute. State Policies in Brief: Counseling and Waiting Periods for Abortion. 2015. http://www.guttmacher.org/ statecenter/spibs/spib_MWPA.pdf [accessed 15 February 2015].

11 Rutledge M. Does counselling really help abortion patients? In: Sachdev P (ed.), Perspectives on Abortion. Metuchen, NJ: Scarecrow Press; 1985:223-235.

12 Vandamme J, Wyverkens E, Buysse A, et al. Pre-abortion counselling from women's point of view. Eur J Contracept Reprod Health Care 2013;18:309-318.

13 BBC News. MPs reject call to change abortion advice. 7 September 2011. http://www.bbc.co.uk/news/ uk-politics-14817816 [accessed 6 November 2014].

14 Curtis P. Reality check: is abortion counselling independent? The Guardian, 6 September 2011. http://www.theguardian. com/politics/reality-check-with-polly-curtis/2011/sep/06/ abortion-health-and-wellbeing [accessed 6 November 2014].

15 Department of Health. A Framework for Sexual Health Improvement in England. 2013. https://www.gov.uk/ government/publications/a-framework-for-sexual-healthimprovement-in-england [accessed 21 February 2015].

16 Brown S. Is counselling necessary? Making the decision to have an abortion. A qualitative interview study. Eur J Contracept Reprod Health 2013;18:44-48.

17 Cohan CL, Dunkel-Schetter C, Lydon J. Pregnancy decision making: predictors of early stress and adjustment. Psychol Women Q 1993;17:223-239.

18 Kero A, Lalos A. Ambivalence - a logical response to legal abortion: a prospective study among women and men. J Psychosom Obstet Gynaecol 2000;21:81-91.

19 Allen I. Counselling Services for Sterilisation, Vasectomy and Termination of Pregnancy. London, UK: Policy Studies Institute, 1985.

20 Cameron S, Glasier A. Identifying women in need of further discussion about the need to have an abortion and eventual outcome. Contraception 2013;88:128-132.

21 Kumar U, Baraitser P, Morton S, et al. Decision making and referral prior to abortion: a qualitative study of women's experiences. J Fam Plann Reprod Health Care 2004;30:51-54.

22 Major B, Cozzarelli C, Cooper ML, et al. Psychological responses of women after first-trimester abortion. Arch Gen Psychiatry 2000;57:777-784.

23 Norman WV, Hestrin B, Dueck R. Access to complex abortion care service and planning improved through a toll-free telephone resource line. Obstet Gynecol Int 2014;2014:913241.

24 King R, Bambling M, Lloyd C, et al. Online counselling: the motives and experiences of young people who choose the Internet instead of face to face or telephone counselling. Couns Psychother Res 2006;6:169-174. 